\title{
Binocular Visual Rehabilitation in Paralytic Strabismus by Botulinum A Toxin Chemodenervation
}

\author{
Myungjin Kim, Helen Lew \\ Department of Ophthalmology, CHA Bundang Medical Center, CHA University College of Medicine, Seongnam, Korea
}

Purpose: To investigate the effect of botulinum A toxin (BTXA) chemodenervation in paralytic strabismus patients without surgical correction.

Methods: A retrospective chart review of 51 patients who were diagnosed as paralytic strabismus and underwent BTXA chemodenervation was performed. The patients were divided into four groups according to the cause of paralytic strabismus of vasculopathy, neoplasm, trauma, and idiopathic. They were also divided into two groups of early and late treatment according to the initiation time of BTXA chemodenervation after the onset of strabismus ( 3 months), and of the initial strabismus type of exotropia and esotropia. We investigated the changes of angle of deviation and diplopia after BTXA chemodenervation.

Results: The average deviation of angles decreased by 25.2 prism diopter (PD) (35.1 to 9.9 PD) in total patients, and the overall success rate was $64.7 \%$ (33 by 51 ), and the there was no statistically significant difference in success rate between each group divided by the cause of paralytic strabismus. According to the treatment timing, the deviation of the angle decreased by 28.0 PD (36.8 to 8.8 PD) in the early treatment group, and 21.3 PD (33.5 to 12.2 PD) in late treatment group at the time of the last postinjective follow-up. According to the initial strabismus type, the average angle of deviation decreased by $20.3 \mathrm{PD}$ (35.6 to 15.3 PD) in exotropia group by cranial nerve 3 palsy, and 24.4 PD (32.5 to 8.1 PD) in esotropia by cranial nerve 6 palsy. Conclusions: BTXA chemodenervation reduced the angle of deviation and the number of patients with diplopia regardless of the cause of paralytic strabismus. Early BTXA chemodenervation can be considered as the first treatment of choice in paralytic strabismus, especially in esotropia patients.

Key Words: Botulinum toxins, Paralysis, Strabismus

Paralytic strabismus is an ocular pathology which one or more of the cranial nerves $(\mathrm{CN})$ innervating the extraocular muscles are affected. Acquired paralysis of $\mathrm{CN} 3, \mathrm{CN} 4$,

Received: April 15, 2021 Final revision: October 12, 2021 Accepted: November 9, 2021

Corresponding Author: Helen Lew, MD, PhD. Department of Ophthalmology, CHA Bundang Medical Center, CHA University College of Medicine, 59 Yatap-ro, Bundang-gu, Seongnam 13496, Korea. Tel: 82-31780-5330, Fax: 82-31-780-5333, E-mail: eye@cha.ac.kr and CN6 that regulate eye movement acting on the extraocular muscles can be resulted from various causes, such as vascular diseases, tumors, and trauma [1-3].

Paralytic strabismus is considered to be treated when there is a diplopia in perceptual visual field or severe abnormality of head position. In the early 1980 s, Scott [4] reported that botulinum toxin is safe and effective in the treatment of strabismus, and then in 1989, botulinum toxin received US Food and Drug Administration approval in the treatment of paralytic strabismus patients over 12 years 
of age. Botulinum A toxin (BTXA) chemodenervation was introduced as a reversible treatment method for acute paralytic strabismus in the early stages but is currently used as one method of general strabismus therapy and also for treatment of chronic paralytic strabismus.

BTXA chemodenervation is simple with few complications, and there is no report on systemic side effects [5]. Administration of BTXA on the extraocular muscles has been gradually considered as an alternative method in the treatment of the strabismus, particularly in paralytic strabismus patients. However, there are few previous studies analyzing the therapeutic effect of BTXA in paralytic strabismus patients quantitatively. The purpose of this study is to investigate the effects of BTXA in patients suffering from diplopia with various causes of paralysis without previous surgical correction history.

\section{Materials and Methods}

A retrospective chart review of 51 patients (males 32 and females 19) who were diagnosed as paralytic strabismus presenting horizontal strabismus (exotropia caused by $\mathrm{CN} 3$ palsy or esotropia caused by CN6 palsy) was performed. Patients who presented vertical strabismus were excluded. Those who were able to be followed up more than 6 months after BTXA chemodenervation were included, while those who had a history of congenital cranial nerve palsy, past strabismus surgery, orbital fractures, and diseases associated with ocular muscles such as myasthenia gravis, thyroid opthalmopathy were excluded. They underwent BTXA chemodenervation (Botox, Allergan, Irvine, CA, USA; Dysport, Ipsen, Slough, UK) from March 2005 to November 2019 at the Department of Ophthalmology of CHA Bundang Medical Center was perfomed. The current study was approved by the institutional review board of CHA Bundang Medical Center (2020-07-066), and all study conduct adhered to the tenets of the Declaration of Helsinki. According to our institutional review board guidelines, informed consents were not mandatory due to its retrospective study design.

Patients' ocular history such as onset of paralytic strabismus, ocular trauma or surgery was thoroughly investigated along with medical history such as diabetes, hypertension, ischemic heart disease, hyperlipidemia associated with vascular causes. All patients were examined for deviation of angle (prism diopter, PD), presence of diplopia, or lid drooping. The deviation of angle was measured by the prism cover test in the primary position, The degree of diplopia $\left({ }^{\circ}\right)$ was defined as the average value of the degree by $30^{\circ}$ intervals in the binocular single vision (BSV) test using the Goldman perimetry. The criterion for success was considered when the correction was made within 10 PD and no central diplopia within $30^{\circ}$ on the BSV test at the last follow-up after injection. All injections were performed under local anesthesia by dropping tetracaine Alcaine (Alcon, Geneva, Swiss) eye drops 5 minutes before injection. Five unit of BTXA diluted by $0.2 \mathrm{~mL}$ normal saline was directly injected to each extraocular muscle (medial or lateral rectus muscle) exposed by Swan conjunctival incision. For BTXA chemodenervation, Botox was injected in 46 patients, and Dysport was injected in five patients. Both BTXA are often used interchangeably and known to be effective at least 3 months.

The patients were divided into four groups of vasculopathy, neoplasm, trauma, and idiopathic according to the causes of strabismus. Vascular disease or brain tumor was defined as a case when the abnormal findings were identified in the cerebral angiography, brain magnetic resonance imaging, or brain computed tomography. Trauma was defined as the case when paralysis immediately occurred after head contusion. Idiopathic was defined if there are not appropriate causes that can result in cranial nerve paralysis. Also, the patients were divided into two groups by 3 months (about 12 weeks) of early treatment group $(<3$ months) and late treatment group ( $\geq 3$ months) according to the time of injection after the onset of strabismus. Additionally, we divided patients into two groups of exotropia group by $\mathrm{CN} 3$ palsy and esotropia by CN6 palsy and investigated natural course of deviation of angle in each group.

Statistical analysis was conducted by IBM SPSS ver. 25.0 (IBM Corp., Armonk, NY, USA) using chi-square test, Kruskal-Wallis test, paired $t$-test, and Wilcoxon singed rank test. Statistical significance was significant if the significant level was less than $0.05(p<0.05)$.

\section{Results}

The number of patients were a total of 51 people (males 32 and females 19). When divided groups according to the 
Table 1. Comparison of baseline demographics and clinical outcomes of botulinum toxin A injection in paralytic strabismus patients according to the etiology of paralysis

\begin{tabular}{|c|c|c|c|c|c|c|}
\hline Variable & $\begin{array}{c}\text { Vasculopathy } \\
\quad(\mathrm{n}=29)\end{array}$ & $\begin{array}{l}\text { Neoplasm } \\
(\mathrm{n}=9)\end{array}$ & $\begin{array}{l}\text { Trauma } \\
(\mathrm{n}=6)\end{array}$ & $\begin{array}{l}\text { Idiopathic } \\
\quad(\mathrm{n}=7)\end{array}$ & $\begin{array}{c}\text { Total } \\
(\mathrm{n}=51)\end{array}$ & $p$-value \\
\hline Sex (male : female) & $17: 12$ & $4: 5$ & $5: 1$ & $6: 1$ & $32: 19$ & $0.252^{*}$ \\
\hline Age (yr) & $61.9 \pm 11.8$ & $53.4 \pm 13.8$ & $46.3 \pm 22.8$ & $50.4 \pm 15.1$ & $57.0 \pm 14.8$ & $0.092^{\dagger}$ \\
\hline $\begin{array}{l}\text { Interval days from onset to injection } \\
\text { (wk) }\end{array}$ & $13.5 \pm 4.2$ & $13.0 \pm 15.8$ & $9.3 \pm 1.4$ & $10.5 \pm 2.7$ & $12.5 \pm 3.5$ & $0.059^{\dagger}$ \\
\hline Initial deviation of angle (PD) & $35.7 \pm 13.2$ & $33.3 \pm 22.9$ & $38.3 \pm 15.1$ & $36.7 \pm 11.4$ & $35.1 \pm 14.9$ & $0.917^{\dagger}$ \\
\hline Initial number of patients with diplopia & $20(69.0)$ & $8(88.9)$ & $6(100.0)$ & $5(71.4)$ & $39(76.5)$ & $0.305^{*}$ \\
\hline Postinjective follow-up period (wk) & $52.6 \pm 3.6$ & $58.6 \pm 9.0$ & $57.5 \pm 2.3$ & $54.5 \pm 2.9$ & $53.5 \pm 2.6$ & $0.442^{\dagger}$ \\
\hline Final deviation of angle (PD) & $14.3 \pm 3.1$ & $6.5 \pm 2.6$ & $5.8 \pm 9.2$ & $8.9 \pm 6.1$ & $9.9 \pm 14.2$ & $0.124^{\dagger}$ \\
\hline $\begin{array}{l}\text { Final no. of patients with relieved } \\
\text { diplopia }\end{array}$ & $25(86.2)$ & $8(88.9)$ & $5(83.3)$ & $5(71.4)$ & $43(84.3)$ & $0.938^{*}$ \\
\hline Success rate & $18(62.1)$ & $7(77.8)$ & $4(66.7)$ & $4(57.1)$ & $33(64.7)$ & $0.814^{*}$ \\
\hline Complication rate & $1(3.4)$ & $1(11.1)$ & $1(16.7)$ & $3(42.9)$ & $5(9.8)$ & $0.045^{*}$ \\
\hline
\end{tabular}

Values are presented as number, mean \pm standard deviation, or number $(\%)$.

$\mathrm{PD}=$ prism diopters.

*Pearson's chi-square test; 'Kruskal-Wallis test.

cause of paralytic strabismus, there was no statistically significant difference in the initial deviation of angles and the initial number of patients with diplopia between each group. At the time of the last postinjective follow-up, the average deviation of angles decreased by 25.2 PD (35.1 to 9.9 PD) in total patients. Divided by the cause of paralytic strabismus, the deviation of angles decreased by $21.4 \mathrm{PD}$ (35.7 to 14.3PD) in vasculopathy group, $26.8 \mathrm{PD}$ (33.3 to 6.5 $\mathrm{PD}$ ) in neoplasm group, $32.5 \mathrm{PD}$ (38.3 to $5.8 \mathrm{PD}$ ) in trauma group, and by $27.8 \mathrm{PD}$ (36.7 to $8.9 \mathrm{PD}$ ) in idiopathic group, respectively. The overall success rate was $64.7 \%$ (33 by 51 ), and there was no statistically significant difference in success rate between each group. In addition, there were no systemic complications after BTXA injection. Only five among the total patients showed complication of lid drooping in the treatment courses, which was spontaneously regressed at the latest follow-up (Table1).

We divided patients according to the time of injection after the onset of strabismus by 3 months. There was no statistical significance in demographic features between the groups. The deviation of the angle decreased by 28.0 PD (36.8 to $8.8 \mathrm{PD})$ in the early treatment group, and 21.3 PD (33.5 to $12.2 \mathrm{PD})$ in late treatment group at the time of the last postinjective follow-up, which showed the statistically significant difference (Fig. 1). Also, the early treat-

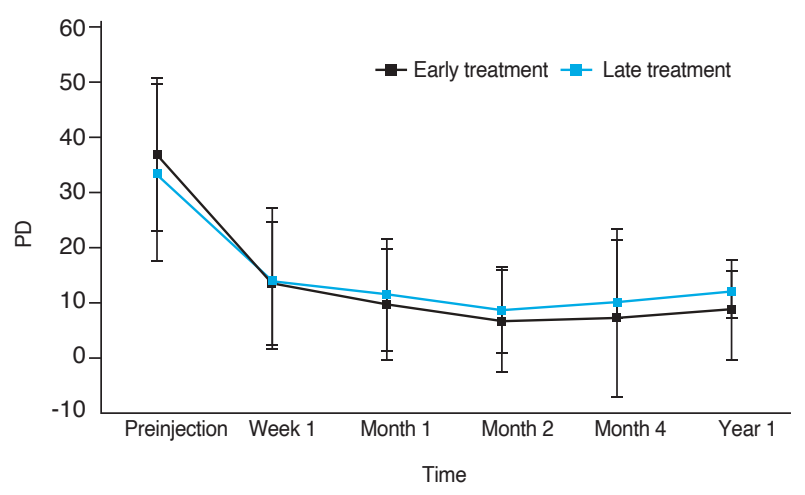

Fig. 1. Postinjective changes of deviation of angle (prism diopters, PD) when divided into early treatment and late treatment. In early treatment group, deviation of angle decreased from $36.8 \pm$ 13.8 PD before injection to $8.8 \pm 9.1 \mathrm{PD}$ after injection, and in late treatment group, deviation of angle decreased from $33.5 \pm 15.9$ PD before injection to $12.2 \pm 3.7 \mathrm{PD}$ after injection. ${ }^{*} p<0.05$.

ment was more effective in the rehabilitation of binocular vision. At 1 month after the BTXA injection, the degree of diplopia decreased by $17.2^{\circ}$ in early treatment group, and $8.4^{\circ}$ in late treatment group, and the outcome was maintained until the last follow-up (Table 2). When dividing groups into exotropia group by $\mathrm{CN} 3$ palsy and esotropia by CN6 palsy, the improvement of the deviation of angle showed a statistically difference from one week after the 
Table 2. Comparison of baseline demographics and clinical outcomes of botulinum toxin A injection in paralytic strabismus patients according to the timing of the treatment

\begin{tabular}{|c|c|c|c|c|}
\hline Variable & $\begin{array}{c}\text { Early treatment } \\
(<3 \text { mon }) \\
(n=24)\end{array}$ & $\begin{array}{l}\text { Late treatment } \\
\qquad \begin{array}{c}(\geq 3 \text { mon }) \\
(n=27)\end{array}\end{array}$ & $\begin{array}{c}\text { Total } \\
(\mathrm{n}=51)\end{array}$ & $p$-value \\
\hline Sex (male : female) & $12: 12$ & $20: 7$ & $32: 19$ & 0.091 \\
\hline Age (yr) & $57.6 \pm 17.3$ & $56.4 \pm 13.0$ & $57.0 \pm 14.8$ & 0.303 \\
\hline CN3 palsy : CN6 palsy & $12: 12$ & $16: 11$ & $28: 23$ & 0.507 \\
\hline Preinjective number of patients with diplopia & $18(75.0)$ & $21(77.8)$ & $39(76.5)$ & 0.475 \\
\hline \multicolumn{5}{|l|}{ Degree of diplopia $\left(^{\circ}\right)$} \\
\hline Preinjection & $45.5 \pm 21.6$ & $44.2 \pm 17.8$ & $44.7 \pm 11.3$ & 0.424 \\
\hline Week 1 & $42.0 \pm 12.5$ & $43.5 \pm 10.1$ & $42.9 \pm 11.7$ & 0.461 \\
\hline Month 1 & $28.3 \pm 14.3$ & $35.8 \pm 17.7$ & $32.3 \pm 9.3$ & $0.048^{*}$ \\
\hline Month 2 & $16.7 \pm 8.4$ & $28.3 \pm 10.3$ & $22.7 \pm 9.5$ & $0.032^{*}$ \\
\hline Month 4 & $13.3 \pm 7.2$ & $20.0 \pm 13.4$ & $17.9 \pm 14.2$ & $0.011^{*}$ \\
\hline Year 1 & $11.2 \pm 6.7$ & $16.3 \pm 7.1$ & $14.5 \pm 7.7$ & $0.023^{*}$ \\
\hline \multicolumn{5}{|l|}{ Success rate } \\
\hline Week 1 & $16(66.7)$ & $11(40.7)$ & $27(52.9)$ & $0.043^{*}$ \\
\hline Month 1 & $14(58.3)$ & $14(51.9)$ & $28(54.9)$ & 0.512 \\
\hline Month 2 & $17(70.8)$ & $16(59.3)$ & $33(64.7)$ & 0.406 \\
\hline Month 4 & $21(87.5)$ & $17(62.9)$ & $38(74.5)$ & 0.166 \\
\hline Year 1 & $20(83.3)$ & $13(48.1)$ & $33(64.7)$ & $0.009^{*}$ \\
\hline
\end{tabular}

Values are presented as number, mean \pm standard deviation, or number $(\%)$.

$\mathrm{CN}=$ cranial nerves.

${ }^{*} p<0.05$.

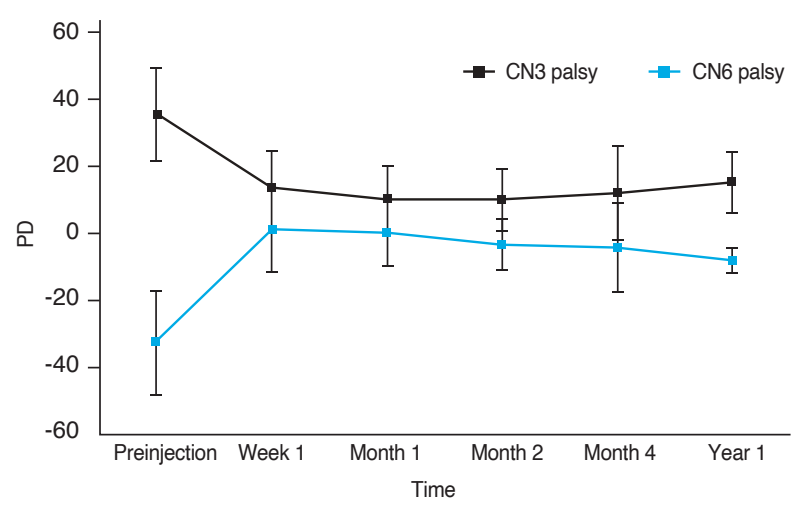

Fig. 2. Postinjective changes of deviation of angle (prism diopters, PD) when divided into exotropia and esotropia patients by cranial nerves $(\mathrm{CN}) 3$ palsy and $\mathrm{CN} 6$ palsy, respectively. In CN3 palsy group, deviation of angle decreased from $35.6 \pm 15.3 \mathrm{PD}$ before injection to $15.3 \pm 9.8 \mathrm{PD}$ after injection. In CN6 palsy group, deviation of angle decreased from $32.5 \pm 19.6$ PD before injection to $8.1 \pm 3.9 \mathrm{PD}$ after injection. Plus means exotropia and minus means esotropia. ${ }^{*} p<0.05$. injection. The average deviation of angle was reduced by 20.3 PD (35.6 to 15.3 PD) in exotropia group by CN3 palsy, and 24.4 PD (32.5 to 8.1 PD) in esotropia by CN6 palsy (Fig. 2).

\section{Discussion}

The causes of paralytic strabismus are very diverse, and there was a difference in the distribution of causes for each study of acquired paralytic strabismus. Rush and Younge [6] reported that most paralysis are resulted from idiopathic causes, Lee et al. [7] reported that the traumatic causes and Park et al. [8] reported that vascular diseases are the most attributing factor of paralytic strabismus. In this study, the most attributing cause of paralytic strabismus was vasculopathy, and then brain tumors, idiopathic and trauma was followed.

Paralytic strabismus caused by microvascular disease of 
diabetes, hypertension, atherosclerosis seems to be naturally recovered within three months, but the paralysis caused by trauma, inflammation, nerve compression seems not to be fully recovered [9]. If the paralysis remains, surgical correction is required, but vertical muscle reposition that is widely used for the treatment of chronic paralysis is at a risk of resulting ischemia in the eye. Repka et al. [9] reported that $41 \%$ of esotropia patients due to chronic lateral muscle palsy without traction disorder were corrected to within 8 PD only with BTXA chemodenervation. In a domestic study, Han et al. [10] reported an average 47.6\% reduction in the angle of deviation after BTXA chemodenervation in chronic paralysis, and the correction was made within 10 PD of the final angle of deviation in $46.2 \%$.

On the other hand, there are not enough previous papers classifying paralysis according to various causes and considering the therapeutic effects of BTXA chemodenervation [11]. According to this study, when dividing paralytic strabismus according to causes as vasculopathy, neoplasm, trauma, and idiopathic, the angle of deviation was reduced only by BTXA chemodenervation. And when defining success as deviation of angle less than $10 \mathrm{PD}$ and no central diplopia within $30^{\circ}$ on the BSV test, the success rate was $62.1 \%, 77.8 \%, 66.7 \%$, and $57.1 \%$, respectively, and showed a higher success rate than conventional studies, suggesting that BTXA chemodenervation can be used as the first treatment of choice in paralytic strabismus of various causes.

Also, in this study we classified patients according to direction of deviation. Exotropia is usually caused by CN3 palsy and esotropia is usually caused by CN6 palsy, respectively. At the final follow-up date, esotropia patients showed higher success rate than exotropia patients. Metz and Mazow [12] reported that among 20 patients with acute CN6 palsy, 18 patients showed deviation correction after botox injection, not requiring surgical correction, and among nine patients with acute $\mathrm{CN} 3$ palsy, all patients showed deviation correction after botox injection, not requiring surgical correction. In contrast, some studies showed that BTXA is often effective in small to moderate esotropia of any cause, and may be an alternative to surgery in these cases $[13,14]$. In our study, esotropia patients with CN6 palsy showed higher success rate. This result is in the same vein with previous study. It can be explained from the neurologic origin of oculomotor muscles. As CN6 innervates only lateral rectus muscle, effect of botox injection can be maximized.

The effect of BTXA occurs after 6 hours of injection inhibiting the end plate potential, and clinically the effect of muscle paralysis appears after 5 to 7 days. This effect is known to last from 3 months to 6 months [15]. In this study, it was confirmed that the effect lasted for at least 4 months. In general, if the paralysis condition is stable, the patient would wait for 6 to 8 months for natural recover. In this study we divided groups as early treatment group and late treatment group in the criteria of 12 weeks. As the time passed after injection, the change in the angle of deviation was greater in the early treatment group than in the late treatment group, and there was a statistically significant difference between the two groups. Previously, treatment was performed when the paralysis was not stabilized after waiting for about 6 to 8 months to stabilize, but according to the results of this study, even if the treatment time is advanced, the success rate for visual rehabilitation is increased and serious side effects do not occur. So early treatment seems to be instrumental to treat diplopia and recover the BSV field in the paralytic strabismus patients. However, the limitations of our study were its retrospective design, being non-comparative and non-randomized. To verify the effect of early treatment of botox in paralytic strabismus patients, prospective trial with randomized design will be needed in the future study.

In conclusion, BTXA chemodenervation reduced the angle of deviation and the number of patients with diplopia regardless of the cause of paralytic strabismus. Early BTXA chemodenervation can be considered as the first treatment of choice in paralytic strabismus, especially in esotropia patients.

\section{Conflicts of Interest}

Chan Yun Kim has been an Editor-in-Chief of the Korean Journal of Ophthalmology since 2020. However, he was not involved in the peer reviewer selection, evaluation, or decision process of this article. Otherwise, no other potential conflicts of interest relevant to this article were reported. 


\section{Acknowledgements}

None.

\section{Funding}

The authors received no financial support for this article.

\section{References}

1. de Camargo GB, Hida WT, Goldchmit M, et al. Paralytic strabismus: review of 24 years at "Santa Casa de Sao Paulo". Arq Bras Oftalmol 2007;70:585-7.

2. Richards BW, Jones FR Jr, Younge BR. Causes and prognosis in 4,278 cases of paralysis of the oculomotor, trochlear, and abducens cranial nerves. Am J Ophthalmol 1992; 113:489-96.

3. Berlit P. Isolated and combined pareses of cranial nerves III, IV and VI. A retrospective study of 412 patients. $J$ Neurol Sci 1991;103:10-5.

4. Scott AB. Botulinum toxin injection into extraocular muscles as an alternative to strabismus surgery. Ophthalmology 1980;87:1044-9.

5. Gomez de Liano R. The use of botulinum toxin in strabismus treatment. J Binocul Vis Ocul Motil 2019;69:51-60.

6. Rush JA, Younge BR. Paralysis of cranial nerves III, IV, and VI. Cause and prognosis in 1,000 cases. Arch Ophthalmol 1981;99:76-9.

7. Lee WY, Kim JH, Shin H. A clinical study of paralytic strabismus. J Korean Ophthalmol Soc 1993;34:549-54.

8. Park UC, Kim SJ, Hwang JM, Yu YS. Clinical features and natural history of acquired third, fourth, and sixth cranial nerve palsy. J Korean Ophthalmol Soc 2005;46:1555-62.

9. Repka MX, Lam GC, Morrison NA. The efficacy of botulinum neurotoxin A for the treatment of complete and partially recovered chronic sixth nerve palsy. J Pediatr Ophthalmol Strabismus 1994;31:79-83.

10. Han SH, Jung JG, Lew H. The effect of botulinum toxin chemodenervation in chronic paralytic strabismus. $J$ Korean Ophthalmol Soc 2000;41:751-7.

11. Stanley EF, Drachman DB. Botulinum toxin blocks quantal but not non-quantal release of $\mathrm{ACh}$ at the neuromuscular junction. Brain Res 1983;261:172-5.

12. Metz HS, Mazow M. Botulinum toxin treatment of acute sixth and third nerve palsy. Graefes Arch Clin Exp Ophthalmol 1988;226:141-4.

13. Kowal L, Wong E, Yahalom C. Botulinum toxin in the treatment of strabismus. A review of its use and effects. Disabil Rehabil 2007;29:1823-31.

14. Dawson EL, Marshman WE, Adams GG. The role of botulinum toxin A in acute-onset esotropia. Ophthalmology 1999;106:1727-30.

15. Pamphlett R. Early terminal and nodal sprouting of motor axons after botulinum toxin. J Neurol Sci 1989;92:181-92. 